\title{
Demographic Characteristics of Patients and Causes Leading to Chronic Renal Failure in Children Admitted to Mashhad Children Hospital
}

\author{
Anoush Azarfar1, Mohammad Esmaeeli' ${ }^{1}$, Yalda Ravanshad ${ }^{2 *}$, Mitra Naseri', \\ Shapour Badiee Aval ${ }^{3}$, Fatemeh Ghanee Sharbaf', Sahar Ravanshad ${ }^{4}$, Hassan Mehrad-Majd ${ }^{2}$, \\ Zohreh Mohammadi ${ }^{1}$
}

${ }^{1}$ Department of Pediatric, Faculty of Medicine, Mashhad University of Medical Sciences, Mashhad, Iran

${ }^{2}$ Clinical Research Unit, Mashhad University of Medical Sciences, Mashhad, Iran

${ }^{3}$ Department of Acupuncture, Faculty of Medicine, Mashhad University of Medical Sciences, Mashhad, Iran

${ }^{4}$ Department of Internal Medicine, Mashhad University of Medical Sciences, Mashhad, Iran

Email: ${ }^{*}$ avanshady@MUMS.ac.ir

How to cite this paper: Azarfar, A., Esmaeeli, M., Ravanshad, Y., Naseri, M., Aval, S.B., Sharbaf, F.G., Ravanshad, S., MehradMajd, H. and Mohammadi, Z. (2017) Demographic Characteristics of Patients and Causes Leading to Chronic Renal Failure in Children Admitted to Mashhad Children Hospital. Open Journal of Nephrology, 7, 47-55.

https://doi.org/10.4236/ojneph.2017.72006

Received: April 17, 2017

Accepted: June 20, 2017

Published: June 23, 2017

Copyright $\odot 2017$ by authors and Scientific Research Publishing Inc. This work is licensed under the Creative Commons Attribution International License (CC BY 4.0).

http://creativecommons.org/licenses/by/4.0/

cC)

\begin{abstract}
Background: An irreversible renal function impairment is called chronic renal failure (CRF) which finally leads to the "end-stage renal disease" (ESRD) and requires renal replacement therapies. The aim of this study is to evaluate the incidence, prevalence of epidemiological indicators (age, sex), and causes of chronic renal failure in children in Mashhad (one of the big cities of Iran). Methods: This is a cross-sectional study that was conducted on patients' records over a seven-year period (2008-2014) in Doctor Sheikh Children's Hospital of Mashhad. The inclusion criteria were all children under 20 years old diagnosed with ESRD, with a GFR less than $15 \mathrm{ml} / \mathrm{min} / 1.73 \mathrm{~m}^{2}$ who were referred to the hospital during the study period. Patients' information, such as age, gender, onset of dialysis, causes of constructing renal failure, and positive or negative antigen of hepatitis B was extracted from their records. Data were analyzed using SPSS 16 software. Results: A total of 326 patients were studied, of which, $56.4 \%$ were male. $45.1 \%$ were from 7 to 18 years. $56.4 \%$ of patients were on hemodialysis and others were on peritoneal dialysis. The most common cause of chronic renal failure in the study was respectively reflux nephropathy (32.9\%), nephrotic syndrome (8.9\%), neurogenic bladder (5.5\%), stones $(2.5 \%)$, glomerulopathy $(2.1 \%)$ and cystinosis $(1.5 \%)$ and $(20.9 \%)$ had unknown cause. During the 7-year period of study considering the treatment outcomes, $69.3 \%$ of patients needed to continue the dialysis; $10.4 \%$ underwent transplantation; $10.4 \%$ unfortunately died despite of treatment and $1.5 \%$ were cured. Conclusions: It is hoped that considering the clinical symptoms of
\end{abstract}


children with chronic renal failure and the diagnosis of the cause, we can reduce complications of the disease with a quick diagnosis and treatment, as well as appropriate follow-up.

\section{Keywords}

Chronic Renal Failure, Children, Chronic Kidney Disease

\section{Introduction}

An irreversible renal function impairment is called chronic renal failure (CRF) [1] [2] which finally leads to the "end-stage renal disease" (ESRD) and requires renal replacement therapies (RRT), such as dialysis and transplant. Chronic renal failure is a chronic disease which has had an increasing rate in recent years; for example, its incidence has increased 10-fold in the last 20 years in the United States [1] [3]. According to the Center for Resource Management and Special Diseases of Ministry of Health, the annual incidence increase of this disease in Iran is about $11 \%$. In 2009 , it was about 40,000 people. The annual incidence rate in Iran is 53 cases per 1 million, and the prevalence is 250 cases per 1 million people. In the USA, the annual incidence and prevalence rates are respectively 200 and 975 cases per million people [1] [4]. There, more than 400,000 Americans have end-stage renal disease, and over 300,000 of these patients need dialysis therapy. Mortality rates are above 20 percent per year with the use of dialysis, with more than half of the deaths driven from cardiovascular diseases [5]. Patients with CRF will not survive without renal replacement therapies. At the end of 2005, 900 million people worldwide were treated by replacement therapy, with $68 \%$ hemodialysis, $8 \%$ peritoneal dialysis, and $23 \%$ renal transplant. In Iran, about $53 \%$ of patients with CRF receive dialysis, and $45 \%$ get transplantation [6]. Chronic Kidney Disease (CKD) is a big public health's problem and many epidemiological researches were done in adults but few studies conducted on pediatrics maybe because of lake of a common definition and well classification of CKD [7]. ESRD can cause excessive mortality and cardiovascular diseases and in children lead to impaired growth [7], so according to some scientific evidences, diagnosing the disease in early stages and providing special care are effective to delay the end-stage renal disease and to decrease the mortality rate; therefore, the costs are reduced, and the quality of life increases [8] [9]. Considering the importance of ESRD prevention and the impact of geographical diversity, and genetic and environmental factors on its development [8], the aim of this study is to evaluate the incidence, prevalence of epidemiological indicators (age, sex), and causes of chronic renal failure in children in Mashhad (one of the big cities of Iran).

\section{Method}

This is a cross sectional study that was conducted on patients' records over a 
seven-year period (2008-2014) in Doctor Sheikh Children's Hospital of Mashhad. The inclusion criteria were all children under 20 years old diagnosed with ESRD, with a GFR less than $15 \mathrm{ml} / \mathrm{min} / 1.73 \mathrm{~m}^{2}$ who were referred to the hospital during the study period. Sampling was non-contingent, and with a census of available records, a total of 326 patients were studied. Based on the cause of the disease, patients were divided into different groups including idiopathic, reflux nephropathy, neurogenic bladder, glomerulopathy and nephrotic syndrome, stones, and other causes such as Cystinosis. Patients were divided into 4 groups of age: birth to 2 years old, 2 to 7 years, 8 to 18 years and over 18 years old. In this research, the causes of ESRD in each age group are studied and evaluated. Patients' information, such as age, gender, onset of dialysis, causes of constructing renal failure, and positive or negative antigen of hepatitis B was extracted from their records. Data was analyzed using SPSS 16 software.

\section{Results}

A total of 326 patients were studied, of which, 184 cases $(56.4 \%)$ were male. The age distribution was $14.1 \%$ under 1 year old, $15.3 \%$ between 1 and 7 years, $45.1 \%$ from 7 to 18 years, and $1.8 \%$ between 18 and 20 years old. In the studied population, $22.4 \%$ of boys were under 1 year old, $20.3 \%$ between 1 and 7 years, $55.9 \%$ from 7 to 11 years and $1.4 \%$ more than 18 years and under 20 years old. Among girls, $14.8 \%$ were under 1 years old, $19.4 \%$ between 1 and 7 years, $62 \%$ from 7 to 18 years, and $3.7 \%$ over 18 years and below 20 years old. Regarding alternative treatments for 326 patients, 184 patients (56.4\%) were on hemodialysis and 142 cases $(43.6 \%)$ were on peritoneal dialysis. Among hemodialysis patients, 97 cases (52.7\%) were boys and 87 (47.3\%) were girls. In patients under peritoneal dialysis, 87 patients $(61.3 \%)$ were male and 55 cases $(38.7 \%)$ were female. The age distribution for alternative treatment methods was: $6 \%$ of patients on hemodialysis were children under 1 year, $16.3 \%$ were $1-7$ years, $79.5 \%$ were 7 - 18 years and $3.6 \%$ were 18 - 20 years old. In patients under peritoneal dialysis, $55.3 \%$ were under 1 year, $27.1 \%$ were 1 - 7 years, $17.6 \%$ were 7 - 18 years old, and none of them was over 18 years old. The most common cause of chronic renal failure in the study population was respectively reflux nephropathy in 118 patients (32.9\%), nephrotic syndrome (8.9\%), neurogenic bladder (5.5\%), stones $(2.5 \%)$, glomerulopathy $(2.1 \%)$ and Cystinosis (1.5\%). In 68 patients $(20.9 \%)$, the cause of chronic renal failure was unknown despite of diagnostic procedures. Other less common causes of chronic renal failure such as lupus, renal hypoplasia, dysplasia, polycystic kidney and HUS were in $10.3 \%$ of the patients. Figure 1 compares the causes of chronic kidney diseases in two different genders. Figure 2 shows the causes of chronic kidney disease by age.

Considering the treatment outcomes in 326 patients during the 7-year period of study, patients were divided into 4 groups: Group 1 patients who needed to continue the dialysis $(69.3 \%)$, group $2(10.4 \%)$ who underwent transplantation, group 3 (10.4\%) who unfortunately died despite of treatment, and finally a small group of patients (1.5\%) who were cured and excluded from treatment. The 


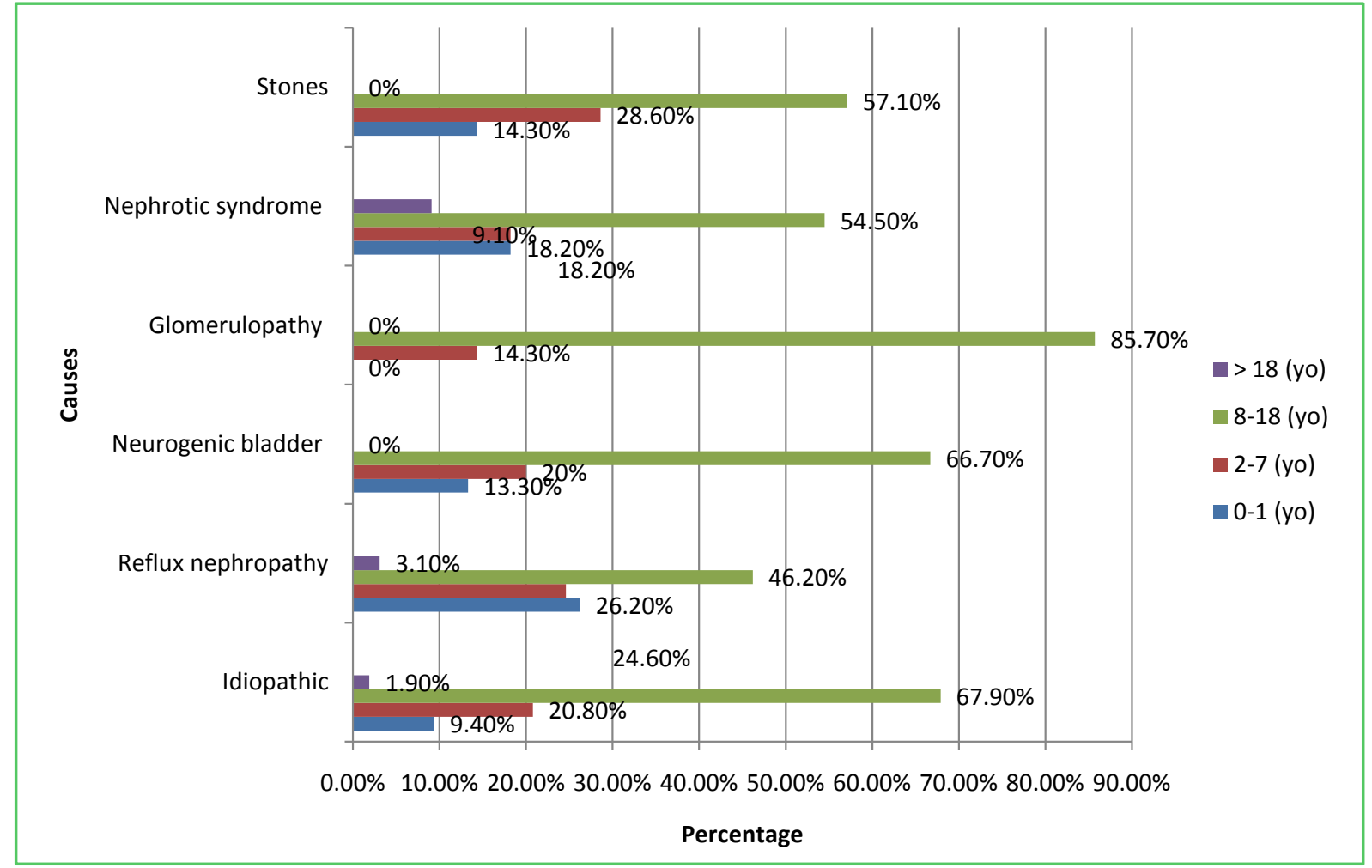

Figure 1. Gender distribution among the different causes of chronic renal failure.

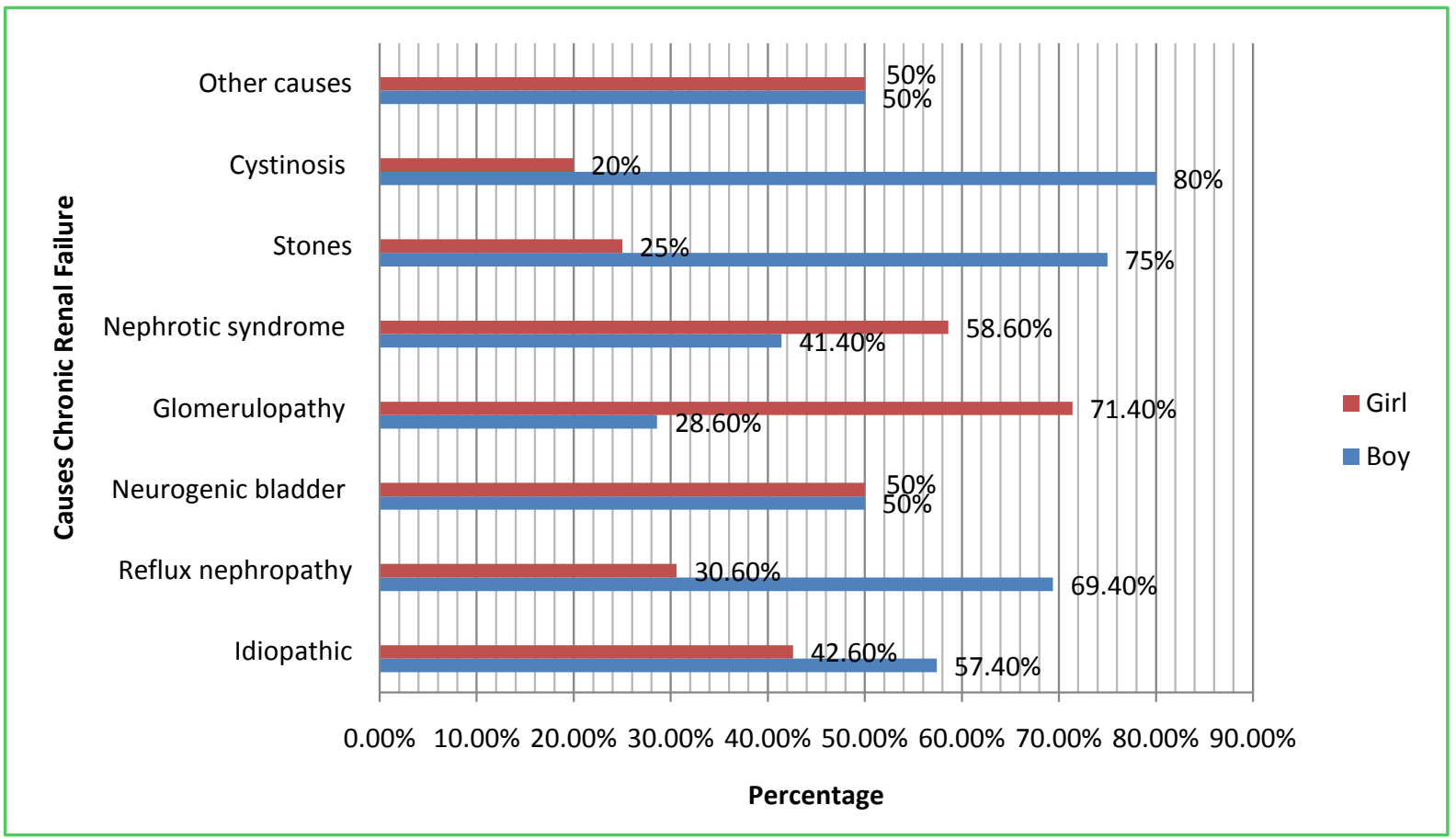

Figure 2. Distribution of different age ranges in causes of chronic kidney disease in the study population (percentage).

outcomes of treatment in different age groups can be seen in Figure 3. The age distribution of different groups of outcomes in boys and girls is shown in Figure 4 and Figure 5 respectively. 


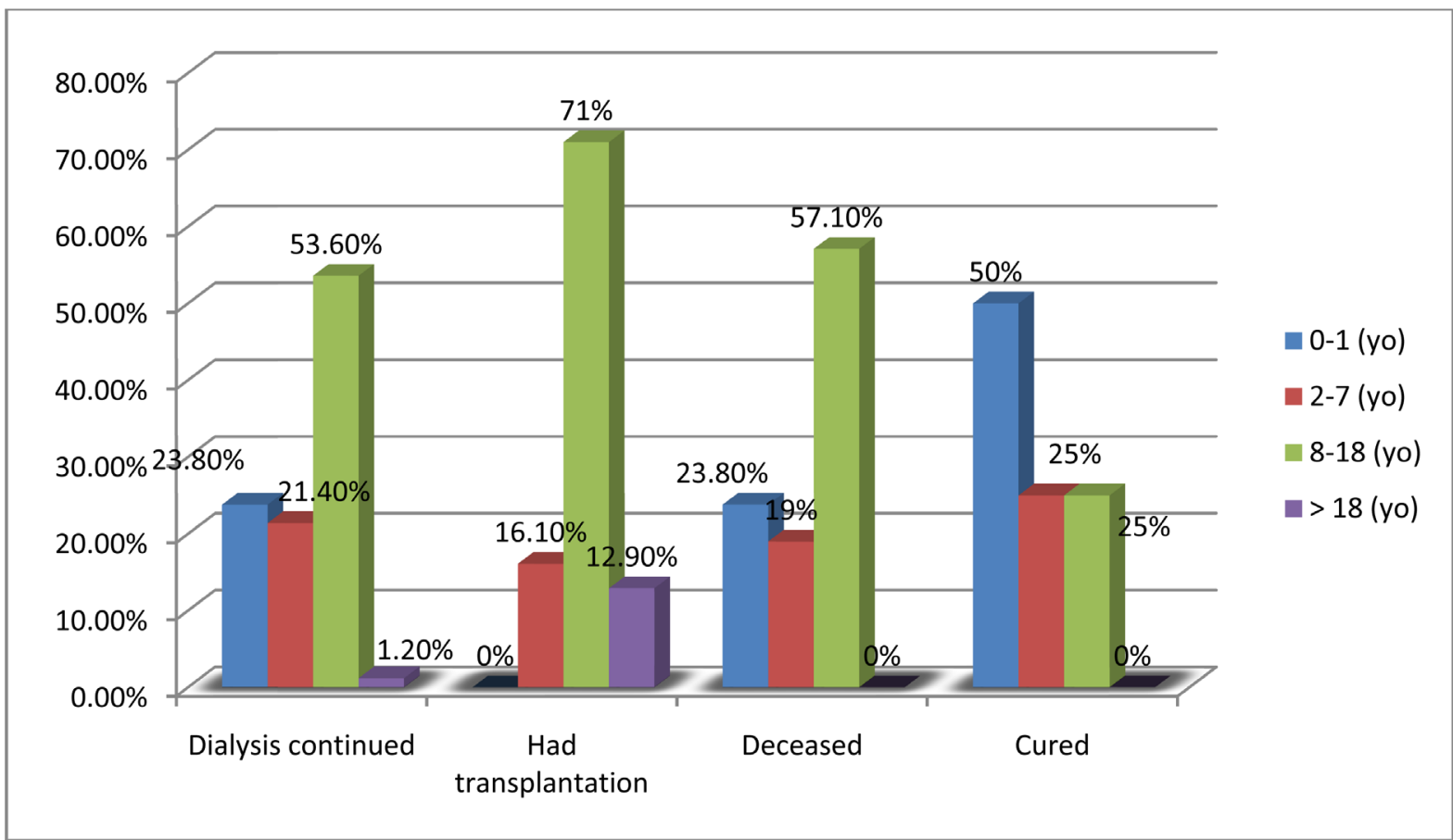

Figure 3. Outcomes of treatment in different age groups.

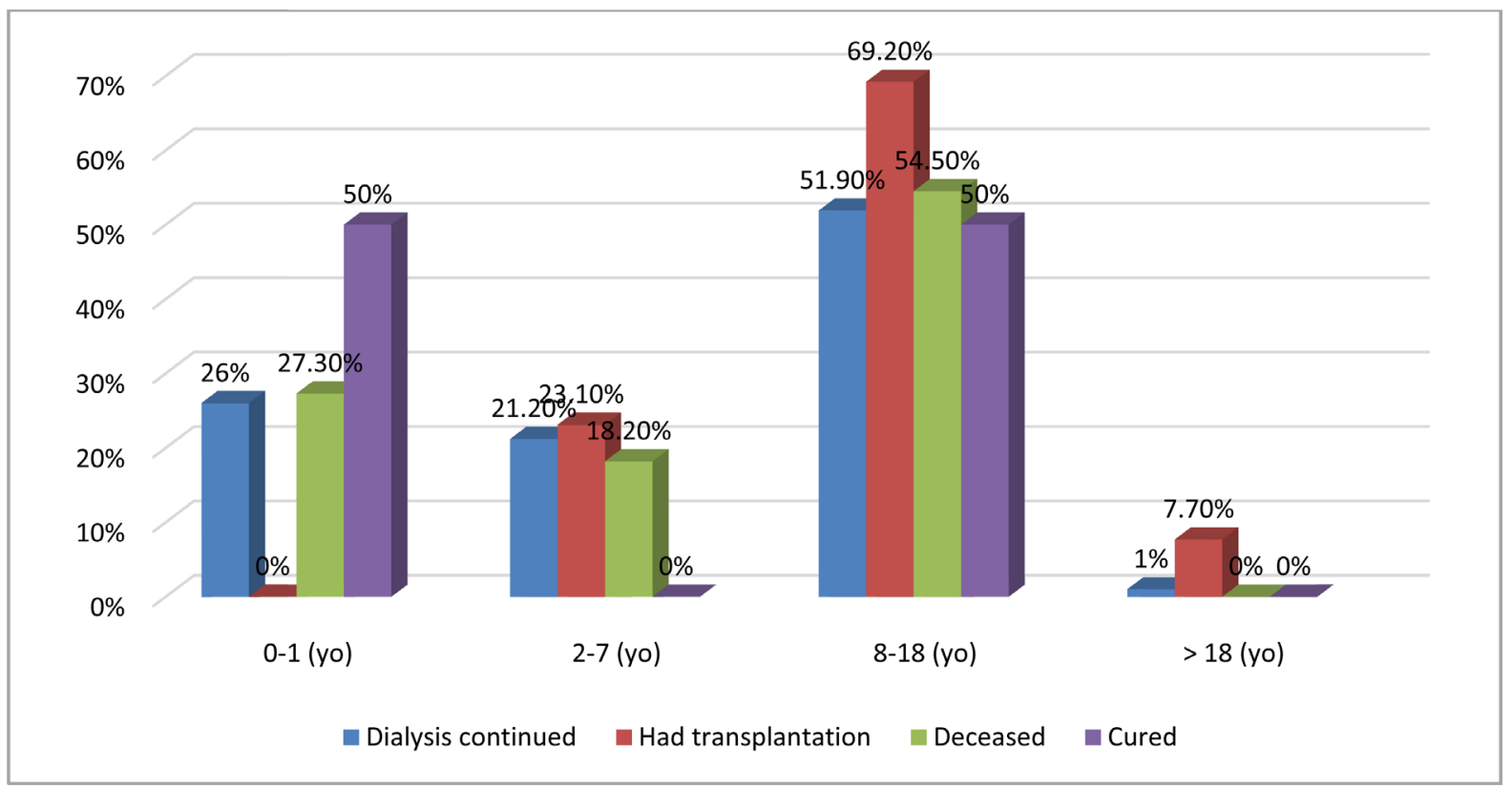

Figure 4. The age distribution of treatment outcomes in boys.

The other parameter which was examined in this study was the type of insurance that covered the patients. Among them, $20.9 \%$ had social security insurance, $32.5 \%$ had health care insurance, and $13.5 \%$ used other types of insurance. For many patients (33.1\%), no information about their insurance was registered in their profile, and some patients, including foreign nationals, did not have any kind of insurance. Considering the hepatitis B antigen, $1 \%$ of patients were positive, $56.2 \%$ negative, and $42.7 \%$ had uncertain results. The frequency of different 


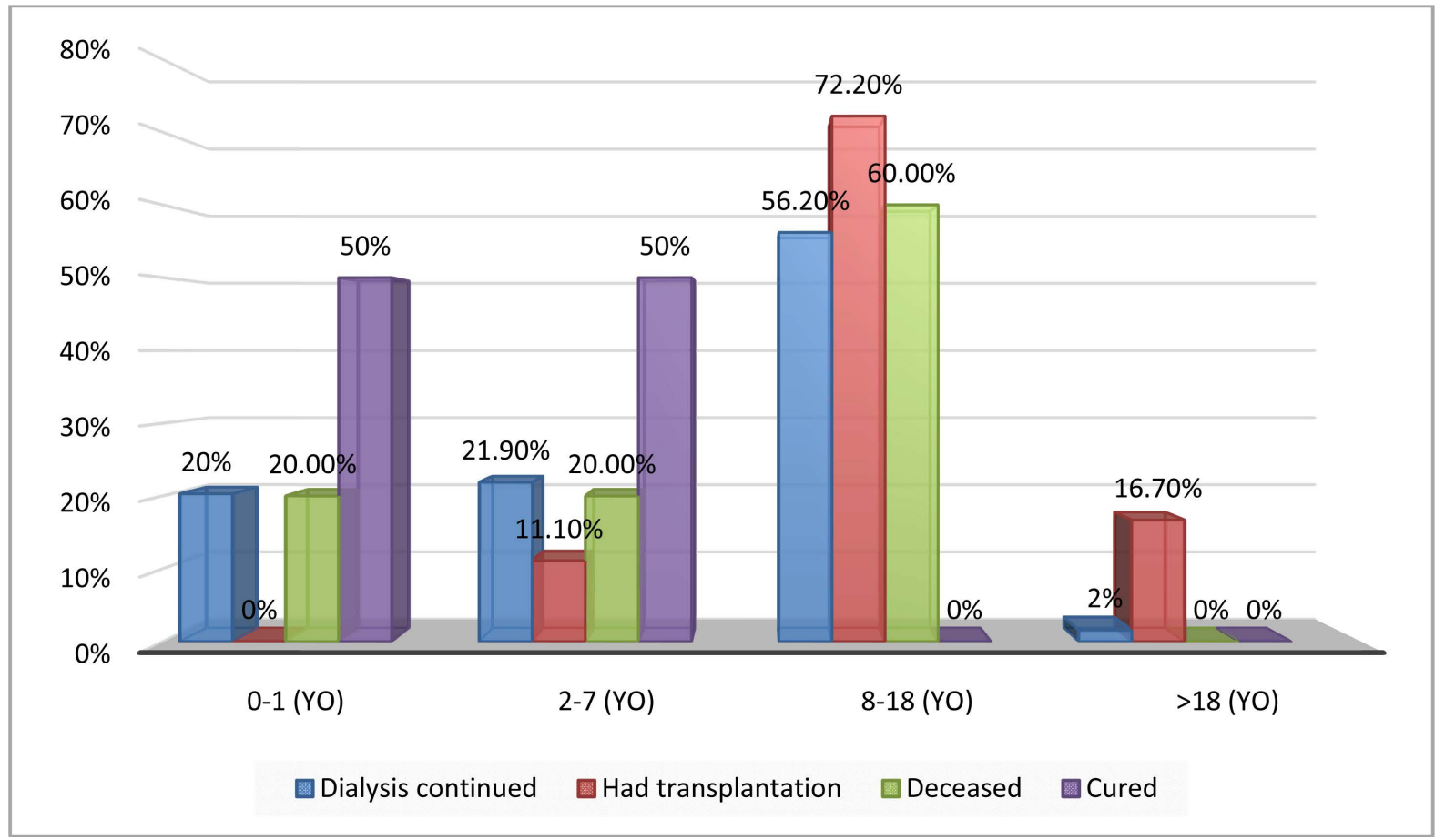

Figure 5. The age distribution of treatment outcomes in girls.

blood groups in patients undergoing hemodialysis was also studied. Among them, $35.4 \%$ were $\mathrm{O}, 25 \%$ were $\mathrm{B}, 31.2 \%$ were $\mathrm{A}$ and $8.3 \%$ were $\mathrm{AB}$.

\section{Discussion and Conclusion}

This research was conducted at the Children's Hospital (Doctor Sheikh) of Mashhad (the referral and main center of pediatrics hemodialysis and peritoneal dialysis in the East of Iran). Totally, 326 ESRD patients in a 7-year period, from 2008 to 2014 were studied. In this study, it was observed that the prevalence of chronic renal failure in boys was slightly higher (56.4\%) than girls, which could be due to a higher incidence of congenital anomalies of the kidney and urinary tract in boys than girls (such as posterior urethral valves). In some studies conducted in other parts of Iran, 53.4\% in Tehran [10], 58\% in Ahvaz [11] and $51.5 \%$ in Shiraz [12], the gender distribution was also in favor of the males and thus consistent with our results.

Patients under dialysis were divided into four age groups. It can be seen that most children in the study population were in 8 - 18 years old age group (45.1\%). This may indicate a delay in identifying the problem and referring patients to hospital. The comparison of gender frequency in different age groups showed that, the percentage of female patients increased with age, so in the age group of 8 - 18 and more than 18 years old, female patients were more.

In this study, reflux nephropathy (32.9\%), nephrotic syndrome $(8.9 \%)$ and neurogenic bladder (5.5\%) were the most common causes of chronic renal failure in patients. Stones $(2.5 \%)$, glomerulopathy $(2.1 \%)$ and cystinosis $(1.5 \%)$ were in the next positions. Note that $20.9 \%$ of cases had unknown causes. Other caus- 
es such as lupus, renal hypoplasia, dysplasia, polycystic kidney and HUS were other less common causes of chronic kidney failure in the studies cases (10.3\%). In other research works in Iran, such as in cities of Ahvaz [11], Tabriz [13] and Tehran [10], the congenital abnormalities of the urinary system were found as the most common cause of CRF, where the reflux nephropathy was reported as $23.1 \%, 31 \%$ and $26 \%$ respectively. The prevalence of reflux nephropathy in other countries such as Turkey [14], Kuwait [15], Tunisia [16] was reported to be $18.5 \%, 61.9 \%$ and $13 \%$ respectively. In China, chronic glomerulonephritis and nephrotic syndrome (52.7\%) were the most common causes of CRF [17].

In our study, the frequency of having stones was $2.5 \%$ and glomerulonephritis was $2.1 \%$. In similar studies, the prevalence of glomerulonephritis has been reported to be in Ahvaz 6.5\% [11], Tabriz 25\% [13], Tehran 10.2\% [10], Pakistan $15.4 \%$ [18], and Tunisia 19\% [16]. Among all the causes we studied, the age group of 8 - 18 years old had the most constituted cases. Gender frequency was also compared among different causes, and the glomerulopathy was found to be of a greater percentage in girls (71.4\%). In neurogenic bladder and those that were classified as other factors, the percentage of boys and girls was equal. Based on the results, reflux nephropathy was the most common diagnosed cause of CRF. Early diagnosis is important for appropriate protective tasks. The most common symptom which leads to discovery of vesicoureteral reflux is urinary tract infections. However, symptoms of these infections, especially at an early age, are nonspecific and misleading. Therefore, attempts to raise awareness in parents about the urinary tract infections, as well as complications arising from lack of rapid treatment and inappropriate follow-up, are essential. Further, taking high prevalence of reflux nephropathy into account as the most common cause of CRF in children helps general practitioners and pediatricians in early identification of the problem and referral to nephrologists. In this study, the cases under study were all the patients on dialysis during a 7-year period (20082014) at Mashhad Children (Dr. Shaikh) Hospital. In a similar study conducted in Tehran, 86\% [19] of the patients required transplantation and mainly had hemodialysis. In a study done in Egypt, 93.5\% [20] of patients with ESRD were undergoing hemodialysis. In another research conducted in China, $15.8 \%$ of patients needed alternative treatment, of which $66.5 \%$ were under dialysis [17]. The gender distribution in all types of dialysis was compared, and the male sex was superior. The frequency of each type of dialysis in different age groups was analyzed. In the age group of $2-7$ years and under 1-year old, priority was with peritoneal dialysis, and in the other two groups, hemodialysis was preferred. Of our patients, $69.3 \%$ of them continued dialysis; $10.4 \%$ received kidney transplant; $10.4 \%$ of patients died during the treatment; and $1.5 \%$ of them improved. The frequency of different age groups in different types of outcome was also calculated. In the cured group, $50 \%$ of people were under 1 year old, but in other groups, the 8 - 18 years old group was higher than others. In all our different outcome groups, the boys were superior, but in kidney transplant group, the number of girls was higher (52.9\%). Type of insurance used by patients was also 
evaluated, and health care insurance with $35 \%$ was the most common. It is hoped that considering the clinical symptoms of children with chronic renal failure and the diagnosis of the cause, we can reduce complications of the disease with a quick diagnosis and treatment, as well as appropriate follow-up. Thus, the social performance of patients would improve, and emotional and psychological problems would be prevented. The financial burdens on the families and on the public health system will also be decreased.

Limitations: The biggest limitation of the study was inaccuracy of patients' registration information that almost in all retrospective studies can be seen. Since in this study it was not possible to access all the nationwide patients referring to hospitals during a year, to assess the prevalence and incidence of chronic renal failure in a more comprehensive population was not possible.

Suggestions: To analyze the incidence and prevalence of chronic kidney failure in pediatric population, prospective studies are recommended, and setting up a diseases registry system especially for chronic diseases should be considered. It is also necessary to plan for informing the parents about the long-term effects, caused by the lack of late visit or follow-up. Also, reminding the high prevalence of reflux nephropathy as the most common cause of CRF in children to general practitioners and pediatricians is helpful for early identification and referral.

\section{References}

[1] Raiesifar, A., Torabpur, M. and Mohsenizad, P. (2010) Causes of Chronic Renal Failure in Hemodialysis Patients of Abadan. IJCCN, 2, 11-12.

[2] Nasabeh, Z. and Hazrati, M. (2008) Medical Surgical Nursing. Tehran Salami-Jame Negar.

[3] Ghods, A.J. and Savaj, S. (2006) Iranian Model of Paid and Regulated Living-Unrelated Kidney Donation. Clinical Journal of the American Society of Nephrology, 1, 1136-1145. https://doi.org/10.2215/CJN.00700206

[4] Lesan Pezshki, M., Matini, M. and Tagadosi, M. (2001) Assessment of Quality of Dialysis in Kashan. FEYZ Journal, 17, 82-87.

[5] Go, A.S., Chertow, G.M., Fan, D., McCulloch, C.E. and Hsu, C.-Y. (2004) Chronic Kidney Disease and the Risks of Death, Cardiovascular Events, and Hospitalization. The New England Journal of Medicine, 351, 1296-1305. https://doi.org/10.1056/NEJMoa041031

[6] Haghighi, A.N., Broumand, B., D'amico, M., Locatelli, F. and Ritz, E. (2002) The Epidemiology of End-Stage Renal Disease in Iran in an International Perspective. Nephrology Dialysis Transplantation, 17, 28-32. https://doi.org/10.1093/ndt/17.1.28

[7] Harambat, J., Van Stralen, K.J., Kim, J.J. and Tizard, E.J. (2012) Epidemiology of Chronic Kidney Disease in Children. Pediatric Nephrology, 27, 363-373.

[8] Sorkhi, H.B.A. (2006) The Assessment of ESRD Causes in 85 Children Refer to Amirkala Hospital. Journal of Babol University of Medical Sciences, 8, 35-39.

[9] Fogo, A.K.V. (1994) Pathophysiology of Progressive Renal Disease. In: Holliday, M.A., Barratt, T.M. and Avner, E.D., Eds., Pediatric Nephrology, 4th Edition, Williams \& Wilkins, Philadelphia, 1228-1240. 
[10] Madani, A.S.M. (2005) The Etiology and Outcome of ESRD in Children Undergoing Hemodialysis in Pediatric Medic Center. Tehran University of Medical Sciences Research Journal, 63, 61-67.

[11] Ahmadzadeh, A., Valavi, E., Zangeneh-Kamali, M. and Ahmadzadeh, A. (2009) Chronic Kidney Disease in Southwestern Iranian Children. Iranian Journal of Pediatrics, 19, 147-153.

[12] Derakhshan, A., Hashemi, G. and Fallahzadeh, M., Eds. (2003) Chronic Renal Failure in Children. Transplantation Proceedings, Elsevier.

[13] Mortazavi, F. (2006) Etiology of Chronic Renal Failure in Children Who Referred to Children's Hospital of Tabriz. Medical Journal of Tabriz University of Medical Sciences, 27, 91-94.

[14] Bek, K., Akman, S., Bilge, I., Topaloğlu, R., Çalışkan, S., Peru, H., et al. (2009) Chronic Kidney Disease in Children in Turkey. Pediatric Nephrology, 24, 797-806. https://doi.org/10.1007/s00467-008-0998-4

[15] Al-Eisa, A., Naseef, M., Al-Hamad, N., Pinto, R., Al-Shimeri, N. and Tahmaz, M. (2005) Chronic Renal Failure in Kuwaiti Children: An Eight-Year Experience. Pediatric Nephrology, 20, 1781-1785. https://doi.org/10.1007/s00467-005-2000-Z

[16] Kamoun, A. and Lakhoua, R. (1996) End-Stage Renal Disease of the Tunisian Child: Epidemiology, Etiologies, and Outcome. Pediatric Nephrology, 10, 479-482. https://doi.org/10.1007/s004670050143

[17] Yang, J. and Yao, Y. (2004) Analysis of 1268 Patients with Chronic Renal Failure in Childhood: A Report from 91 Hospitals in China from 1990 to 2002. Chinese Journal of Pediatrics, 42, 724-730.

[18] Jamro, S., Channa, N., Shaikh, A. and Ramzan, A. (2003) Chronic Renal Failure in Children. The Journal of the Pakistan Medical Association, 53, 140-142.

[19] Madani, K., Otoukesh, H., Rastegar, A. and Van Why, S. (2001) Chronic Renal Failure in Iranian Children. Pediatric Nephrology, 16, 140-144. https://doi.org/10.1007/s004670000522

[20] Safouh, H., Fadel, F., Essam, R., Salah, A. and Bekhet, A. (2015) Causes of Chronic Kidney Disease in Egyptian Children. Saudi Journal of Kidney Diseases and Transplantation, 26, 806-809. https://doi.org/10.4103/1319-2442.160224

\section{Submit or recommend next manuscript to SCIRP and we will provide best service for you:}

Accepting pre-submission inquiries through Email, Facebook, LinkedIn, Twitter, etc. A wide selection of journals (inclusive of 9 subjects, more than 200 journals)

Providing 24-hour high-quality service

User-friendly online submission system

Fair and swift peer-review system

Efficient typesetting and proofreading procedure

Display of the result of downloads and visits, as well as the number of cited articles

Maximum dissemination of your research work

Submit your manuscript at: http://papersubmission.scirp.org/

Or contact ojneph@scirp.org 